\title{
An Ethnographic Autobiography of a Short-Term Study Abroad Experience
}

\author{
Jordan W. Smith \\ North Carolina State University \\ Dept. of Parks, Recreation and Tourism Management \\ Box 8004 Biltmore \\ Raleigh, NC 27695-8004 \\ Phone: (435) 830-6294 • E-mail: jwsmit12@ncsu.edu
}

\begin{abstract}
The purpose of this article is to explore the unique contributions the study abroad experience can make to the knowledge and skills acquired while studying parks, recreation, and tourism management. These unique contributions are analyzed through an ethnographic autobiography of the author's personal engagement as a graduate student in a summer study abroad course to Kenya. Data consist of the author's personal travel journal, which was recorded throughout the course. Open and axial coding reveal three concepts that captured the extent to which the study abroad experience led to acquired knowledge that otherwise had not been gained through classroom-based learning: culture, connections between park management and social well-being, and community-based conservation efforts in action. Analysis also revealed one concept, analytical and inquisitive problem solving, which encapsulated the distinctive learning processes facilitated through participation in the course. Also, the unique value the study abroad experience offers for parks, recreation, and tourism department programs is explored.
\end{abstract}

KEYWORDS: International studies, alternative pedagogy, qualitative analysis 


\section{Introduction}

Parks, recreation, and tourism students are increasingly facing a post-academic environment that requires a solid understanding in an extremely diverse array of disciplines. Students emerging from parks, recreation, and tourism programs must be capable of working collaboratively with other professionals across the diverse range of leisure service providers. As the field of parks, recreation, and tourism management is inherently diverse, students also need to be knowledgeable about the various actors and institutions which operate and interact at a variety of scales, from local to global. The increasing demands placed on students are not unfounded as the changing global marketplace is well cited. In fact, during an international education policy statement, former U.S. President Bill Clinton opened with these remarks:

To continue to compete successfully in a global economy and to maintain our role as a world leader, the United States needs to ensure that it's citizens develop a broad understanding of the world, proficiency in other languages, and knowledge of other cultures (2000).

Many parks, recreation, and tourism departments acknowledge and foster students' need to be knowledgeable of international issues and to work collaboratively across disciplinary boundaries through flexible curriculum development and required internships. As students and parks, recreation, and tourism programs are feeling the effects of globalization, many departments are employing a diverse array of pedagogical methods to more thoroughly educate and prepare students.

The use of study abroad programs is one of those unique methods now being realized by parks, recreation, and tourism departments. Study abroad experiences have long tradition of being alternative teaching methods that expose students to unique real-world experiences. Within the parks, recreation, and tourism field, study abroad programs can be utilized to expose students not just to the amazingly complex and diverse nature of the field but also to unique cultures, environments, individuals, languages, and wildlife. While more and more programs are beginning to employ or explore study abroad programs as valuable pedagogical tools, many students wishing to gain international experience have ventured outside their home departments and attached themselves to programs focusing on ecology, geography, planning, sociology, or other specific academic disciplines. Knowing that students often seek out diverse, engaging, and unique learning experiences such as study abroad implies that they desire to gain personally created experiences and knowledge which is unachievable within the traditional classroom setting. The realization of personal motivations to engage in study abroad experiences often changes how the student sees and experiences the world. Frequently however, personal change and the realization of personal learning motivations are left undocumented in the literature; too often data are abandoned in personal journals and required writings. The purpose of this article is to explore the unique contributions that the study abroad experience can make to an individuals' perspective on the world, their role in it, and the unique learning experiences that can emerge through the process. These distinctive contributions are explored through an 
autoethnographic record of participation in a summer study abroad experience to Kenya's Rift Valley.

\section{A Brief History of Study Abroad}

The courses that evolved into modern study abroad programs originated in the 1880s and 1890s. Indiana University began offering a summer study abroad course in 1882, shortly after which Princeton was offering volunteer programs to serve in Asia (Hoffa, 1998). Early courses however, were far removed from the systematic, interdisciplinary, and well-organized programs available today at most universities. Early courses were founded on the idea of fostering cross-cultural understanding and increasing foreign language proficiencies. One of the first formal study abroad programs for undergraduate students was offered in the early 1920s by the University of Delaware (Kochanek, 2009). The Delaware Foreign Study Plan, as it became known, was available to students from universities all over the northeastern United States who were studying modern language and wished to develop their foreign language skills in Paris, France and in later years, Switzerland and Germany. Similar academic programs were soon offered at other major universities. By the time America entered World War II in the early 1940s, 31 programs were available to U.S. students (Hoffa, 1998). The end of the war marked an increase in study abroad participation as the now widely known Fulbright scholarship program was introduced in 1946 . While the number of programs offered to students increased soon after the war, opportunity to engage in study abroad was limited to the students who were financially capable of incurring additional costs to tuition (Bolen, 2001). Yet, soon thereafter widespread appeal began to flourish as financial aid became readily accessible to most students. Greater participation can also be attributed to U.S. educational policies that made a university education possible to students from more racially and financially diverse backgrounds. In the 1985-86 academic year, nearly 50,000 students participated in formal study abroad programs (Institute of International Education, 2008a). In the following 13 years, participation in study abroad courses nearly tripled to 129,770 . By the turn of the century, more than 2,500 programs were offered to U.S. students (Institute of International Education, 2000). According to the most current data available, 241,791 students studied abroad in the 2006-07 academic year (Institute of International Education, 2008b). Despite the fact overall numbers are on the rise, less than three percent of all American undergraduates participate in a study abroad program (Hayward \& Siaya, 2001). Given students' increasing interest and enrollment in study abroad programs, many universities have established offices of study abroad solely for the purpose of facilitating and streamlining a broad array of programs. Indeed, the study abroad experience has become a significant component to the educational offerings at most U.S. universities.

Possible Outcomes of Participation in Study Abroad

Most current study abroad programs couple an educational program with accommodations like food, lodging, and access to popular destinations that are associated with and characterize the host country. Study abroad programs intend 
for students to be engrossed in a foreign culture. Ideally the immersion in a new cultural context will increase a student's ability to think globally, reduce ethnocentricism, decrease the use of negative cultural stereotypes, and expand the sophistication of how students think about others (Cushner \& Brislin, 1996). The immersion in another culture is also intended to increase emotional resilience, flexibility, perceptual acuity, and personal autonomy (Kitsantas, 2004). Arguing that the study abroad experience should be seen as consumed good, a prepackaged experience, Bolen states that "because consumption is linked to identity, students already expect that consuming this culture will assist them in making decisions about who they are as Americans, wor $\equiv$ and human beings" (2001, p. 186). The focus of Bolen's argument is that an $\bar{m}$ dividual's self-identity and their worldviews are shaped by the experience and knowledge gained from being engaged in foreign cultural and environmental contexts.

Participation in a study abroad experience can also result in future economic benefits. A program brochure for a study abroad course at Boston University succinctly states "You are no longer competing for jobs solely with graduates from the university down the street, you are competing with bright, multi-lingual students from around the world" (Perkins, 1995, p. 1). The potential for future employers to look favorably upon students who have international experience through a study abroad program has been conveyed in an array of fields from chemistry (Davies, 1996) to engineering (Blumenthal \& Grothus, 2008) and law (Gest, 1994). As Bolen argues, "Study abroad now fits into the consumer ethos as a means of earning more money and enjoying the American standard of living" (2001, p. 187).

However, study abroad programs do not produce solely positive experiences for participating students, negative consequences have also been noted. One criticism is that citizens from less-developed countries may see American students as having vast amounts of purchasing power (Herbert, 2000). It is not infrequent for students who travel to developing countries to be seen as "rich Americans". Bolen (2001) has noted specifically that:

In various African countries, female students describe receiving frequent proposals of marriage because they are seen as a meal ticket to the good life of Americans. In Europe, American students often talk about being left with the bill for a night out because they are seen as being able to afford it.

In theory, the idea that citizens from host countries perceive all Americans as wealthy tourists produces a barrier to more direct cultural contact and social understanding.

Study abroad programs can also have their legitimacy threatened by a perception that programs are merely catering to the leisure time desires of American students. It's been argued that American society has become increasingly centered on active leisure time pursuits, moving away from the $19^{\text {th }}$ century model of organizing life around work (Rodgers, 1978). From this perspective, one could argue the study abroad experience is simply functioning as a means to participate in a glorified leisure experience while not completely divorcing oneself from a sociallydemanded work ethic. This criticism may threaten the credibility of study abroad 
programs as alternative pedagogical tools that can be used in addition to the traditional academic setting.

\section{Purpose}

As previously mentioned, the outcomes and experiences of participation in a study abroad program are frequently lost in student journals, or required course writings, never to be utilized as descriptively rich sources of qualitative data. The author had the opportunity to participate in a summer study abroad course during the summer of 2007 that had a focused concentration on park and natural resource management. Knowing the study abroad experience is rarely evaluated through qualitative data analysis, the author saw his participation in the course as an opportunity to explore the unique contributions the experience had on his education, ability to learn, and individual worldview.

Guiding this line of inquiry are two distinct questions that were chosen prior to analysis based on three criteria. First, they are relevant to the empirical analysis of the study abroad experience (i.e., they explore lessons learned and the uniqueness of the experience). Second, they are relevant to educators and administrators within the parks, recreation, and tourism management field. And finally, they are fully capable of being explored within the limits of the data available. Given these criteria, the questions serve as a guiding direction from which the data can be systematically deconstructed and interpreted. The first of these two questions was formulated by a desire to know how and in which ways the content of the course facilitated the acquisition of new knowledge. This question was: What knowledge was gained from the study abroad experience that wasn't otherwise acquired through classroom-based learning? Knowledge and assumptions that were already held prior to participation in the course and the course readings obviously influence the interpretation of daily life in a foreign country. However, the purpose of this question is to differentiate the experience of studying abroad itself from knowledge gained prior to the field portion of the course. The second question was chosen based on a desire to systematically analyze the unique learning opportunities and processes that were facilitated by the course. Subsequently, the analysis was guided by the following question: What unique learning processes occurred through participation in the course?

\section{Theoretical Framework}

The topic of study abroad courses has previously been explored through quantitative data analysis of students' perceptions before and after a study abroad course (e.g., Kehl, 2006; Nash, 1976). However, quantitative analysis in the social sciences favors a post-positivist research paradigm, often restricting the number of "how" and "why" questions which can be asked. A quantitative approach may also be inappropriate to understanding the study abroad experience as a complex and deeply personal experience. Perceiving the study abroad experience as a lived experience from a more interpretive epistemology acknowledges an often unordered and inconsistent social world. Given this acknowledgement, alternative and more interpretive research paradigms are warranted to answer questions that cannot be addressed under more post-positivist approaches. 
While many researchers acknowledge that different research questions can be addressed through different paradigms, debate is still ongoing as to how that research is presented (Dupuis, 1999; Parry \& Johnson, 2007). This paper acknowledges the need to explore research questions unanswerable by more traditional post-positivist paradigms through alternative and more appropriate forms of inquiry that reflect the assumptions of an interpretive worldview. Creative analytic process (CAP) has been presented in the literature as a method of research representation that addresses the divergent line of inquiry enabled by interpretive data analysis. CAP allows for data to be presented in such a manner that disconnects it from the "orderly, neat, and consistent" form favored under more traditional paradigms. Data presented through the CAP can often take the form of autoethnography, performances, personal stories, poetry, and visual images (Parry \& Johnson, 2007).

The use of an ethnographic autobiography allows for the researcher to portray himself or herself as the subject of the research (Henderson et al., 2008). As with all autoethnography, this approach enables the researcher to examine the self within shifting social and psychological contexts (Berger, 2001; Couser, 2005; Vidal-Ortiz, 2004). The approach acknowledges that a researcher's individual experiences are data and how one makes sense of them and reflects on them influences the analysis undertaken (Henderson, 2006). Using an ethnographic autobiography does not presume that interpretive research is necessarily better than research grounded in a post-positivist paradigm, it simply acknowledges that to answer different questions, different methodologies and presentations are warranted (Richardson, 2002). For the purpose of this research, the use of an ethnographic autobiography is an appropriate method to describe the study abroad experience in personal and contextually-rich detail.

\section{Methods}

Program Description

Environment and Society in Kenya's Rift Valley was a study abroad course offered jointly by Utah State University's Department of Environment and Society and Egerton University in Njoro, Kenya. As the course syllabus stated, the purpose of the course was to "expose undergraduate and graduate students in the Department of Environment \& Society to issues concerning society and natural resource management as they apply to a developing country context."

Specifically, the course consisted of pre-trip readings, in-class discussions, an exam on course readings, the field experience in Kenya, and a summary group report and presentation. The course was offered to both graduate and undergraduate students within the department. In total, three graduate students and three undergraduate students participated in the two-week long course. The author, at the time of the course in the summer of 2007, was a graduate student pursuing a Master's degree in Recreation Resource Management. 


\section{Data collection}

Data for this research was acquired through a personal travel journal kept during the field course describing the experience of the course. The personal travel journal was an opportunity to process the daily experiences of the course (e.g. what was done, heard, seen, etc.). The journal was also an opportunity to reflect on the day's occurrences (e.g. what was felt about things that were done, heard, and seen during the day's events) as they were occurring, when memories, feelings, and emotions were strongest. Advice on writing a more complete, contemplative, and analytical journal were offered by the course instructors in the syllabus:

The key to your successful journal is to treat it is a personal space to reflect, ... so do not simply recount the events of your day. REFLECT on those events. We ask that you work on your journal daily, picking a time and a place that is comfortable and allows for a bit of quiet reflection. The end of the day might work well, but you choose a time that works well for you. You will want to complete a journal entry each day, beginning with your departure day and ending on the day before the last day of the course. Start by writing briefly about what you did during that day. Where did you go, who did you talk to, what did you see, hear, smell, taste, etc.? Anything that stands out particularly for you. Then spend some quiet time reflecting on these events, before beginning to write the larger reflective section... We are looking for you to be personally honest in your writing. We will not judge your feelings and hope that you will not either: All feelings and reactions, no matter how "politically incorrect" are valid and appropriate.

\section{Data Analysis}

The open and axial coding process described by Corbin and Strauss (2008) was utilized to analyze the data. The personal travel journal of the author was transcribed and imported into Atlas.ti where all coding was completed. Given the disperse, random, and unorganized nature often associated with personal journals, the two guiding questions mentioned previously were used as a starting point to guide in open coding data and connecting emergent concepts. Open coding was used to identify the concepts that directly related to the framework provided by the guiding questions. Once open coding was completed, axial coding organized and related the concepts to one another. Memos were also used throughout the analysis process to ensure a written record of the analytic process to further address trustworthiness.

The analysis process was iterative and resulted in several integrative concepts. Through the open and axial coding process three concepts captured the extent to which the study abroad experience led to acquired knowledge that otherwise had not been gained through classroom-based learning. These concepts are: culture, connections between park management and social well being, and community-based conservation efforts in action. Analysis also revealed one dominant concept, analytical and inquisitive problem solving, which encapsulated the distinctive learning processes that occurred through participation in the course. Each of these concepts is presented in the composite ethnographic autobiography using data from the travel journal. 


\section{Results}

\section{Culture}

Perhaps predictably, the most salient pieces of knowledge gained from the study abroad experience that were distinctive to the course involved learning about new cultures, values, traditions, and ways of life. For many, gaining this type of knowledge is the purpose of studying abroad. Students and educators studying abroad often anticipate a crewal awakening, but not knowing how that process will occur often leads to the $\overline{\bar{\sigma}}$ at amounts of anticipation. The following narrative account reflects the cultural knowledge I gained throughout the study abroad experience.

Day 1 - Once off the plane, we navigated our way to the international arrivals desk and then on to our luggage claim. The first thing that struck me was the lack of organizational structure, not only in the airport, but throughout the city as well. From the free-for-all at the luggage claim area to the chaos of the traffic we encountered on the way back to the hostel, the lack of socially determined order will take some getting used to.

Day 2 - Nairobi in the daylight struck me first of all with the absolute masses of people occupying the street, and secondly with the abject poverty that they are living and working in. The facades of the busy market can easily distract one from the rows of tin roofed, brick and mud walled houses that lay behind. The air in the streets smells of smoke from people burning their trash in the ditches between the market and the road.

Day 3 - We went to an outdoor market that is open only two days a week. We were dogged by the suppliers to purchase food but were advised by our cook, Jackline and guide, David (pseudonyms),, to let them do the purchasing for us as the retailers will always charge a premium to white customers. The market was a literal mad house with people selling everything from sugarcane to charcoal.

Day 4 - We left Hippo Camp for good and headed south along the east side of the lake, arriving at Lake Naivasha Country Club along the southeastern edge. It was an old colonial club that still had most of the appearance of a highbrow club that you might imagine from the mid 50s. Short manicured grass, impeccable gardens; servers complete with towels draped over one arm, and wicker chairs, the whole package.

[Later the same day] we passed a man who was breaking rocks. He was sitting on the side of road and literally turning big rocks into little rocks. It really is an eye-opener to see how even with people living here for the last 100,000 years, the social evolution of cultural traditions and lifestyles remains firmly engrained in everyday lives, to the point that technological innovations are either eschewed or inaccessible.

Day 10 - Leaving Nakuru we passed Gilani's Supermarket along Club Road and saw a man getting beaten on the sidewalk. This apparently is a common occurrence if someone steals from the market and tries to flee. The scene was very hectic as eight to ten men ganged up on the thief and kicked him until he was finally able to get away down a side road. In a country where corruption is so widespread and known, I wonder if the people who came to display their own method of street justice were acting so because of their distrust or lack of faith in the enforcement and judicial system, or because they are aware of the consequences that corruption has levied on their country and are trying desperately to move past a history based out of crime and violence. 
Day 12 - [At a meeting with local community members] we shifted gears and departed from the traditional dialogue of watershed and local community issues to one of broader social understanding and cultural awareness. In an open discussion we exchanged questions about livelihoods, the contrast of climates and topography between Utah and Kenya, traditional wedding and cultural ceremonies, and female/male roles within the household. It truly was a unique experience to see the expression on their faces as we explained the differences between urban American life and agropastoral village life in the Rift Valley of Kenya.

Day 14 - [The professor] explained to the group how in traditional Muslim families, the men are served and eat before the women do. But his family is more liberal as they all usually eat together. That is just another example of how this trip has allowed me to experience different cultures and religions that I never would have been able to otherwise.

\section{Connections Between Park Management and Social Well Being}

While many educators in the field of parks, recreation, and tourism management teach and write about how management actions cause and have consequences for local communities and broader society, rarely can they enable students to appreciate and experience these connections first hand. Yet, the study abroad experience allowed me unique insight and an opportunity to recognize and interact with these connections.

Day 5 - We departed for Lake Nakuru National Park and I was amazed by the stark contrast between Nakurutown and the park. The dilapidated urban area abuts the pristine and well-guarded park. The Kenya Wildlife Service (KWS) [analogous to the U.S. National Park Service] obviously is the dominant federal organization in Kenya as evidenced by all the revenues it is able to bank from its parks. But obviously through corruption and poor government, little of the tourist dollar actually reaches the working or poor classes.

Day 6 - The KWS showed us the sewage treatment plant that the park utilizes to clean the wastewater and stormwater runoff from Nakurutown. It wasn't what I was expecting. Fourteen filtration ponds followed by a grassy plain, and a stormwater runoff system that relies on gravity to filter out the silt and debris. It's a system that is stressed by the input of waste from Nakurutown. And one that has problems compounded by the unique climate and soil of the Rift Valley.

Day 9 - The work [of researchers in the region] seems to be very promising, as the local communities seemed very anxious to be involved in the process. The researchers mentioned that it gives the communities a common gathering point and a spark for communications in how they perceive their environment and how they desire for their community to change.

\section{Community-based Conservation Efforts in Action}

Similar to the connections between park management and social well-being, educators often have difficulty explaining the applied side of the courses they teach. Not because of a lack of awareness or desire, but simply because of time and mobility restraints that limit the potential of classroom-based courses. By actually being out in the field, the study abroad experience facilitated this type of knowledge acquisition for the author. 
Day 7 - Here we were introduced to several community members and the projects that the KWS has undertaken to inform local communities about the importance of wildlife and other environmental issues in the region. The first project was one in which the KWS supplies the community with tree seedlings for growing on a small plot of land near the park. The intent is for the community members to transplant the trees back into their villages once they have reached a certain maturity. So far, the project is very small in scale and very few, if any, trees have been transplanted. The second project was one where individuals from Leeds University in England have collected funds for a stormwater collection basin in the village from which local community members were able to store water for sustained use of their livestock during the dry season. This project proved the most promising, as local community members were able to see some tangible benefit to getting involved in the project and maintaining the tank and collection system. So far, they have collected enough funds to construct 22 tanks and collection systems. The final project that we visited was a school that was making efforts to teach children the importance of natural resource and environmental quality. Given the fact that in 2003 President Kibaki enabled primary education to be free and enrollment numbers skyrocketed, the mere attempt to teach any environmental studies at all is commendable.

Day 11 - Departing from Bogoria Lodge we first visited a project site of one of the World Wide Fund for Nature's (WWF) efforts to preserve flamingo populations by encouraging proper land use practices upstream of the lake to maintain or improve the quality of water flowing into Lake Bogoria. The WWF does this by empowering local communities through collaboration and the formation of co-operative agreements in which locals receive assistance from the WWF if they agree to put into place more sustainable land use practices like growing feed for their livestock instead of having an open grazing system.

The first project was a livelihood diversification scheme in which the WWF assisted a local community, who had culturally been pastoralists, to develop a secondary source of income through honey production. The WWF provided assistance by teaching the community safer and more productive harvesting methods... On the output end, the community returns $50 \%$ of its revenue to the WWF. The honey is sold to a larger company within Kenya that is able to distribute it nationally.

The second project was very similar to the first in that it financially assisted local farmers to change farm production, from only maize to a diversified crop of paw paws, bananas, sugar cane, tomatoes, and sweet potatoes. In return, the WWF again receives a portion of the return. A final project was also visited where the WWF assisted, financially, in the conversion of traditional rangeland to seed grown feed lots, with the purpose being to reduce animal dependence on the riparian vegetation surrounding th $\equiv$ r.

Analytical and inquisitive problem solving

While the three emergent concepts above represent the distinct knowledge gained from the author's experience, the analysis also sought to determine what unique learning processes occurred through participation in the course. The analysis revealed personal analytical and inquisitive problem solving skills were facilitated by the course in a manner that more traditional pedagogical methods may not have 
allowed. The following narrative provides examples of how engagement in the course facilitated the analytical and inquisitive problem solving process.

Day 3 - We departed for the southeastern edge of the lake where our group interviewed several fishermen who fish from a government owned corridor entering the banks of Lake Naivasha. They complained of a recent ban on fishing imposed by the fisheries department to improve quality and quantity of fish stocks in the lake. They have been able to adapt to new species being introduced into the lake over the last 12 years (the length of time that they have been living in the area). They also complained of a double standard of equality imposed upon them and not on the flower industry for accountability of lake health. They trust the government very little, and it sounds like they have no outlets into the public arena from which to be heard.

Day 3 - We returned to the southern edge of the lake, continuing up nearer the Mau escarpment. We met with a man named Jimiyu Chebusiri (pseudonym). He, with the help of outside backers, has been able to install what he calls a "zero impact" agricultural and cultivation system. Keeping his animals penned and feeding them grains grown on site, then using the animal waste to fertilize his fields and also turn it into methane for energy to heat his stove. This system is in stark contrast to those seen around his village where land is usually rented from an owner, then cleared for traditional agricultural uses, corn rows, and livestock holding facilities (they are grazed in a nearby forest where no grazing fee is required). His techniques are promising but they must overcome significant obstacles, namely decades of vernacular cultural knowledge and monetary requirements to initially establish widespread "zero impact" systems.

Overall, I am seeing a lake with tremendous potential for market enhancement (economic growth) and environmental restorations. But I also see a lake with an incredibly complex set of social, political, cultural, and economic issues that must be more completely understood and dissected to reveal any true processes that could be undertaken to better work toward that end, economic and environmental health.

Day 4 - The locals were out enjoying their Sunday afternoon on the beach. It makes me wonder about the connections between poverty and the quality of the regions eco-system. How would the lake be different if the local communities lived like much of the rest of the world? Would the wildlife still be "exotic"? Would the attention to environmental health be different than it is now? Would the use of the lake change? And if so, how and why? These are all things that I think are under-appreciated when it comes to fully appreciating the cultural, environmental, and geographic uniqueness of the region.

Day 8 - Changing cultural practices and aiding community members in their adaptation to a new landscape will prove to be extremely difficult as researchers and aid workers must infuse new technologies and ideas into the communities while realizing that traditions and historical practices as well as cultural identity must be respected.

Day 11 - After reviewing these project [those noted above under Community based conservation efforts in action Day 11] locations, I believe that the WWF is doing positive things for the local communities' livelihoods, as well as the quality of the river. However, the efforts seem to require a substantial investment in human capital and social trust for there to be any progress or "buy in" by the local community members. Secondly, it was unclear how the efforts of the WWF had changed the livelihoods of more than a select 
number of individuals within the community. Some real data on income sources and dependence on traditional livelihoods would be more than helpful in determining the true extent to which the WWF's community development programs have affected the local people's lives.

Day 13 - The visit [to the Fisheries Department at Lake Baringo] truly did shine a light on the lack of natural resource management within Kenya as the director was constantly referring to operations of Non-Governmental Organizations (NGOs) and research teams when asked how the lake was currently being managed. The Fisheries Department at Baringo only has 8 staff, one boat, and no motor. The lack of formal infrastructure within these government agencies is truly sad as foreign research teams and projects have little interest beyond data collection and NGOs can only operate within a framework established by the ruling government. The extent of the corruption and difficulty that the federal government makes in doing business can be difficult to comprehend for someone who is not familiar with the history and political mechanisms within the country.

\section{Discussion}

Analyzing data from my personal travel journal to determine what knowledge was gained from the study abroad experience that otherwise had not been acquired through classroom-based learning enabled me to systematically deconstruct the learning experience, bringing forth the most salient and distinctive concepts. Guided by two deliberately chosen research questions, the analysis was able to provide rich, contextually loaded data that supports the findings. The concepts that emerged have several implications for administrators and educators within the parks, recreation, and tourism field.

First, the study abroad experience can be an increasingly valuable pedagogical tool to give students an educational experience that is both more liberal in its breadth and more intensive and personal in its depth. Students are exposed to diverse world cultures, languages, traditions, norms, and mores, that enable them not only to be more competitive in a shifting, more global marketplace, but also to be better global citizens when they leave their departments than when they arrived. The study abroad experience also allows students to experience firsthand the applied and multi-disciplinary foundations that characterize the parks, recreation, and tourism field.

The world over the past several decades has becoming increasingly "globalized". Yet the extent to which increased connections between individuals, cultures, institutions, and economies has had an impact on parks, recreation, and tourism scholarship and education hasn't been given adequate attention in the literature. Several scholars have argued that recreation scholarship needs to adopt a more global or cross-national perspective (Iwasaki, Nishino, Onda, \& Bowling, 2007; Valentine, Allison, \& Schneider, 1999). While a more global research agenda is certainly warranted, the results of this study suggest that more globally-focused curriculums are also needed if students are to be prepared for the increasingly global economic marketplace. Making opportunities available for students to study abroad is a direct mechanism through which administrators can incorporate a focus toward international and global issues into their curriculums. 
The second implication for administrators and educators within the parks, recreation, and tourism field revolves around the qualitative difference and personal impact that study abroad opportunities can contribute to students' educational experiences. The study abroad experience can influence a student's self-identity, allowing them to frame their worldview within a global context. Alternative pedagogies, such as study abroad, allow students to acquire knowledge and develop personal skills that will remain personal and meaningful. Learning within a different context enables students to challenge their preconceived ideas of the world; it also allows them to formulate personal opinions that are grounded in experience and memory. Scholars who study human learning have made a clear distinction between rote learning and meaningful learning (Ausubel, 2000). Rote learning refers to the process of incorporating new knowledge into cognitive structures "arbitrarily" and "non-substantively" (Novak, 2002). In contrast, meaningful learning occurs when a learner chooses conscientiously to integrate new knowledge to knowledge already possessed (Novak, 1994). Rote learning, characterized by memorization and verbatim recall of answers for tests, has been shown to become irretrievable from long-term memory, and inapplicable to new contextual situations (Edmondson \& Novak, 1992). The study abroad experience is clearly a pedagogical approach that engrosses itself in meaningful learning. The results of this study suggest the study abroad experience offers a unique opportunity to conscientiously engage with new knowledge, in turn supporting the development of inquisitiveness, creative thinking, and the development of cognitive structures that are more capable of adapting and being applied to new environmental contexts.

Lastly, the study abroad experience is an increasingly important educational tool given the relatively new era of climate change, globalization, and energy crisis. If the students who are emerging from school today are able to offer insights and significant contributions to the important role that parks, recreation, and tourism management plays in a world of energy and climate instability, they must be equipped with a global perspective of the challenges we face. The ability to see alternative solutions cannot come without a greater awareness of the problem.

I sincerely hope that the ethnographic autobiography of my personal study abroad experience will potentially serve as a call for a renewed effort to provide parks, recreation, and tourism students with alternative learning mechanisms such as study abroad. Ancillary to this desire, I also encourage faculty members who are already involved in study abroad programs to provide students an outlet to share the knowledge they have gained and experiences they have had while studying abroad. Personal travel journals are excellent tools; however, their contents are often lost to time. Students should and need to think critically and analytically about their experiences if they are to influence existing personal knowledge and perspectives. 


\section{References}

Ausubel, D. P. (2000). The acquisition and retention of knowledge: A cognitive view. Boston, MA: Kluwer Academic.

Berger, L. (2001). Inside out: Narrative autoethnography as a path toward rapport. Qualitative Inquiry, 7(4), 504-518.

Blumenthal, P., \& Grothus, U. (2008). Developing global competence in engineering students: U.S. and German approaches. Online Journal for Global Engineering Education, 3(2), 1-12.

Bolen, M. (2001). Consumerism and U.S. study abroad. Journal of Studies in International Education, 5, 181-200.

Clinton, W. J. (2000). International education policy: Memorandum for the heads of executive departments and agencies. Retrieved January 8, 2009, from http://www.pub.whitehouse.gov/ uri-res/I2R?urn:pdi://oma.eop.gov.us/2000/4/20/3.txt.1.

Corbin, J., \& Strauss, A. (2008). Basics of qualitative research: Techniques and procedures for developing grounded theory (3rd ed.). Thousand Oaks, CA: Sage.

Couser, G. T. (2005). Disability and (auto) ethnography. Journal of Contemporary Ethnography, 34(2), $121-142$.

Cushner, K., \& Brislin, R. (1996). Intercultural interactions: A practical guide (2nd ed.). Thousand Oaks, CA: Sage.

Davies, G. (1996). Experiential, cooperative, and study abroad education. Journal of Chemical Education, 73(5), 438-440.

Dupuis, S. L. (1999). Naked truths: Towards a reflexive methodology in leisure research. Leisure Sciences, 21(1), 43-64.

Edmondson, K., \& Novak, J. D. (1992). Toward an authentic understanding of subject matter. In S. Hills (Ed.), The history and philosophy of science in science education (Vol. 1, pp. 253-263). Kingston, Ontario, Canada: Queen's University, Faculty of Education, and the Mathematics, Science, Technology, and Teacher Education Group.

Gest, T. (1994). Going international. U.S. News $\mathcal{E}$ World Report, 116(11), 66.

Hayward, F. M., \& Siaya, L. M. (2001). Public experience, attitudes, and knowledge: A report on two national surveys about international education. Washington, DC: American Council on Education.

Henderson, K. (2006). Dimensions of choice: Qualitative approaches to parks, recreation, tourism, sport, and leisure research (2nd ed.). State College, PA: Venture.

Henderson, K., Oakleaf, L., James, P., Swanson, J., Moore, A., Edwards, M., et al. (2008). The experience of learning/teaching qualitative research approaches: An ethnographic autobiography. Schole, 23, 21-32.

Herbert, S. (2000, September 4). Fears for Oxford Colleges as Americans buy a way in. The Daily Telegraph, p. 13.

Hoffa, W. (1998). Study abroad: A parent's guide for parents of college and university students contemplating a study abroad experience. Washington, DC: NAFSA, Association of International Educators.

Institute of International Education. (2000). Academic year abroad 2000-2001. New York: Author.

Institute of International Education. (2008a, November 17). Open doors online: Report on international education exchange. Retrieved January 8, 2009, from http://www.opendoors. iienetwork.org/.

Institute of International Education. (2008b, November 17). U.S. study abroad up 8\%, continuing decade-long growth. Retrieved January 9, 2009, from http://opendoors.iienetwork. org $/ \mathrm{p}=131592$.

Iwasaki, Y., Nishino, H., Onda, T., \& Bowling, C. (2007). Leisure research in a global world: time to reverse the western domination in leisure research? Leisure Sciences, 29(1), 113-117. 
Kehl, K. L. (2006). Differences in self-efficacy and global-mindedness between short-term and semester-long study abroad participants of selected Christian universities. Unpublished doctoral dissertation, Baylor University.

Kitsantas, A. (2004). Studying abroad: The role of college students' goals on the development of cross-cultural skills and global understanding. College Student Journal, 38, 441-453.

Kochanek, L. (2009). Study abroad celebrates 75th anniversary. Retrieved January 7, 2009, from http://www.udel.edu/PR/SpecialUDelivery/vol1nol/anniversary.html.

Nash, D. (1976). The personal consequences of a year of study abroad. The Journal of Higher Education, 47(2), 191-203.

Novak, J. D. (1994). A view on the current status of Ausubel's assimilation theory of learning. CADMO: Giornale Italiano di Pedagogia, Sperimentale, Didattica, Docimologia, Technologia dell'instruzione, 2(4), 7-23.

Novak, J. D. (2002). Meaningful learning: The essential factor for conceptual change in limited or inappropriate propositional hierarchies leading to empowerment of learners. Science Education, 86(4), 548.

Parry, D. C., \& Johnson, C. W. (2007). Contextualizing leisure research to encompass complexity in lived leisure experience: The need for creative analytic practice. Leisure Sciences, 29, 119-130.

Perkins, T. (1995). Boston University international programs: Academic year 1995-1996. Boston: Boston University.

Richardson, L. (2002). Writing sociology. Cultural Studies $\Leftrightarrow$ Critical Methodologies, 2(3), 414-422.

Rodgers, D. T. (1978). The work ethic in industrial America, 1850-1920. Chicago, IL: University of Chicago Press.

Valentine, K., Allison, M., \& Schneider, I. (1999). The one-way mirror of leisure research: A need for cross-national social scientific perspectives. Leisure Sciences, 21(3), 241-246.

Vidal-Ortiz, S. (2004). On being a white person of color: Using autoethnography to understand Puerto Ricans' racialization. Qualitative Sociology, 27(2), 179-203. 